\title{
Fabrication of High Transparency Diamond-Like Carbon Film Coating on D263T Glass at Room Temperature as an Antireflection Layer
}

\author{
Chii-Ruey Lin, ${ }^{1,2,3}$ Hong-Ming Chang, ${ }^{2}$ and Chien-Kuo Chang ${ }^{3}$ \\ ${ }^{1}$ Institute of Mechatronic Engineering, National Taipei University of Technology, Taipei 10608, Taiwan \\ ${ }^{2}$ College of Mechanical and Electrical Engineering, National Taipei University of Technology, Taipei 10608, Taiwan \\ ${ }^{3}$ Graduate College of Mechanical and Electrical Engineering, National Taipei University of Technology, Taipei 10608, Taiwan \\ Correspondence should be addressed to Chii-Ruey Lin; crlin@ntut.edu.tw
}

Received 7 December 2012; Revised 28 January 2013; Accepted 1 February 2013

Academic Editor: Ho Chang

Copyright ( 2013 Chii-Ruey Lin et al. This is an open access article distributed under the Creative Commons Attribution License, which permits unrestricted use, distribution, and reproduction in any medium, provided the original work is properly cited.

\begin{abstract}
This study intends to deposit high transmittance diamond-like carbon (DLC) thin films on D263T glass substrate at room temperature via a diamond powder target using the radio frequency (RF) magnetron sputtering technique. Moreover, various process parameters were used to tune the properties of the thin films by using the Taguchi method. Experimental results show that the content of $\mathrm{sp}^{3}$ bonded carbon decreases in accordance with the effect of the substrate temperature. In addition, the hardness of all as-deposited single-layer DLC films ranges from 13.2 to $22.5 \mathrm{GPa}$, and the RMS surface roughness was improved significantly with the decrease in sputtering pressure. The water repellent of the deposited DLC films improved significantly with the increase of the $\mathrm{sp}^{3}$ content, and its contact angle was larger than that of the noncoated one by 1.45 times. Furthermore, the refraction index $(n)$ of all as-deposited DLC films ranges from 1.95 to 2.1 at $\lambda=600 \mathrm{~nm}$. These results demonstrate that the thickness increased as the reflectance increased. DLC film under an RF power of $150 \mathrm{~W}$ possesses high transmissive ability $(>81 \%)$ and low average reflectance ability $(<9.5 \%)$ in the visible wavelengths (at $\lambda=400-700 \mathrm{~nm})$.
\end{abstract}

\section{Introduction}

Diamond-like carbon (DLC) containing a large proportion of combined $\mathrm{sp}^{3} / \mathrm{sp}^{2}$-hybrid bonds has extreme properties similar to diamonds [1-5]. It is possible to prepare DLC films for several important applications in the fields of mechanical manufacturing, solar energy devices, electricity devices, and so forth, owing to their excellent properties, including high hardness, high thermal conductivity, high electrical resistivity, low infrared (IR) absorption, transparency to visible light, hydrophobic behavior, and chemical inertness [6-11]. Recent researches and technology have focused on keeping high transmission with reduced reflectance capability to maintain enough visibility in a protectively antireflecting coating for solar energy; this type of optical coating can be applied to the surfaces of lenses and other optical devices to reduce reflection $[12,13]$. Thus, this study proposes a novel technique which can keep the surface water repellent and improve the surface by lowering reflection.

In this study, hydrogen-free DLC films were deposited at room temperature by using radio frequency $(\mathrm{RF})$ magnetron sputtering with a unique target consisting of artificial nanodiamond powders. The nano-diamond powder used in this work was a commercial product, which was synthesized by the high-pressure high-temperature (HPHT) method. The diamond target fabricated in the RF magnetron cathode for DLC sputtering was composed of high-purity diamond powder with a mean particle size of about $100 \mathrm{~nm}$. The nanodiamond target sputtering process easily formed high $\mathrm{sp}^{3}$ content on the thin film at a low temperature $[6,10,14]$. For optical applications, previous studies have indicated that the optical properties of DLC films vary between those of 
diamond ( $\mathrm{sp}^{3}$ bonding) and graphite ( $\mathrm{sp}^{2}$ bonding). The wavelengths of the refractive index $(n)$ and extinction coefficient $(k)$ of DLC depend on the C energies on the substrate [15]. On the other hand, the most important parameter of the film is the thickness. DLC films have been applied as both protective and antireflective coatings for optoelectronic devices and silicon solar cells that are even more demanding in terms of well-defined thickness and the specific optical properties of the films $[16,17]$. It is well known that light transparency and hydrophobic behavior depend on D263T glassbased materials. The D263T glass substrate is a borosilicate glass that is produced by melting very pure raw materials. This type of substrate has high luminous transmittance. The properties of D263T glass represent the standard for optical glass. The performances of films deposited onto D263T glass substrate vary under different parameters such as sputtering power, working distance, sputter pressure, and deposition time in the sputtering process. Experiments have carried out to understand the effects of these process parameters. Further discussion of the results of these experiments will be provided in the following. The purpose of this work was to deposit thin films on D263T glass substrate under various process parameters to tune the properties of the thin films by using the Taguchi method, wherein the only estimation standard for steadiness and robustness was to determine a variance index identified as the signal to noise ratio $(S / N)$ [18-22]. Moreover, a lesser number of experiments are desired in the sputtering process when using the Taguchi method. This study utilized the Taguchi method to design experiments involving as-deposited hydrogen-free DLC films on D263T glass substrates at room temperature by the RF magnetron sputtering system. The experiments focused on the significance of the process parameters of DLC films, indicating that using four factors with three levels represents an $\mathrm{L}_{9}\left(3^{4}\right)$ orthogonal array. According to these analysis results, fewer experiments (only nine experimental runs) were required to study all levels of input parameters. We also filtered out some effects owing to statistical variation [21]. The four factors include sputtering power, working distance, sputtering pressure, and deposition time. The ranks of each factor were considered as major influences in the experiment via the analysis of variance (ANOVA) approach. Thus, the Taguchi method was utilized as an engineering methodology to find a correlation between control factors and product characterization. The corresponding microstructure, optical performance, and mechanical properties of the thin films were identified by a scanning electron microscope (SEM), X-ray photoemission spectroscopy (XPS), atomic force microscopy (AFM), a UV/Vis spectrophotometer, and contact angle goniometry, respectively. XPS can be summed up as the measurement of kinetic energy of the inner or valence electron ejected by used an incident photon with energy $h v$. The binding energy is sensitive to chemical bonds in a compound and is related to the energy of ionization. The measured kinetic energy of photoelectrons generally ranges between 0 and $1000 \mathrm{eV}$ in DLC films, and the depth of inspection is about $40-50 \AA$. As mentioned previously, XPS is a highly sensitive analyzer which offers a better method for the surface properties of the sample. The $\mathrm{Cls}$ peak of a-C:H films is in the range from 284.5 to $286.4 \mathrm{eV}$, as the full width at half maximum (FWHM) of the $\mathrm{Cls}$ peak of a-C:H is around 1.6-1.7 eV, relatively larger than the corresponding FWHM for diamond and for graphite. XPS was carried out the $\mathrm{Mg}$ $\mathrm{K}-\alpha$-line, which analyzed about the top $4 \mathrm{~nm}$ of the film, indicating that the spectra were determined with the Cls peak of $\sim 285 \mathrm{eV}$. Also present was the O1s peak of $531 \mathrm{eV}$, owing to surface chemisorbed oxygen species. Thus, the $\mathrm{sp}^{2}: \mathrm{sp}^{3}$ ratios determined using XPS data will represent the surface values [23-25].

\section{Experimental Methods}

This study employs the Taguchi methods to design the experiment in which as-deposited hydrogen-free DLC films are deposited onto D263T glass substrate $(10 \times 10 \times 0.55 \mathrm{~mm})$ at room temperature by an RF magnetron sputtering system with an artificial diamond powder target of 3 inches in diameter as the magnetron source in an argon plasma. The diamond powder as the sputter target was easily synthesized with high $\mathrm{sp}^{3}$ content in thin film at low temperature by using the proposed sputtering method owing to the nanocrystalline diamond powders. With a larger fraction of $\mathrm{sp}^{3}$ bonding, the properties of DLC coatings will be skewed toward diamond. The content of $\mathrm{sp}^{3}$ is very much dependent on the ion energy during deposition [26]. The DLC films were deposited by using sputter and the sputtering power; working distance, sputter pressure, and deposition time were used as the deposition parameters. In the sputtering process, the heat flux to the substrate relates to the thermalization coefficient which is the ratio of particle energy at the substrate to that at the target. This ratio depends on the product of gas pressure and substrate-target distance [27]. Therefore, D263T glass substrates were placed at distances between 8 and $10 \mathrm{~cm}$ from the target with a rotation speed of $15 \mathrm{rpm}$. DLC films have been deposited at RF powers ranging from 150 to $200 \mathrm{~W}$ and at an $\mathrm{rf}$ of $13.56 \mathrm{MHz}$ with capacitive coupling, and the film deposition time was in the range from 0.5 to $2 \mathrm{~h}$ under sputter pressure ranging from 1 to $5 \mathrm{mTorr}$. The corresponding three level experimental designs for depositing DLC films onto D263T glass substrate are listed in Tables 1 and 2. This study carried out the experiments by using the sputtering process conditions for an $\mathrm{L}_{9}\left(3^{4}\right)$ orthogonal array in all asdeposited DLC films. The structured bonding of the DLC films under different deposition parameters was examined by $\mathrm{X}$-ray photoelectron spectroscopy (XPS). The contact angle of the samples was measured by the sessile drop method using a First Ten Angstroms 1000B (FTA 1000B) contact angle goniometry. The liquid was dropped by using $3 \mu \mathrm{L}$ droplets of deionized (DI) water. All measurements were carried out at room temperature. A UV/Vis spectrophotometer was used to measure the corresponding optical transmittance of the DLC films deposited onto D263T glass substrate. The corresponding all the specimen's optical properties of refractive index $(n)$, extinction coefficient $(k)$, transmittance, and reflectance and film thickness were determined by 
TABLE 1: The design of the experiment defines the deposition parameters of DLC films for each factor and level.

\begin{tabular}{lcccc}
\hline Symbol & Factor & Level 1 & Level 2 & Level 3 \\
\hline A & RF power (W) & 150 & 175 & 200 \\
B & Working distance (cm) & 8 & 9 & 10 \\
C & Sputtering pressure (mTorr) & 1 & 3 & 5 \\
D & Deposition time (h) & 0.5 & 1 & 2 \\
\hline
\end{tabular}

TABLE 2: Design of experiments (DOE) according to $\mathrm{L}_{9}\left(3^{4}\right)$ orthogonal array.

\begin{tabular}{lcccc}
\hline $\begin{array}{l}\text { Specimen } \\
(\mathrm{GD})\end{array}$ & $\begin{array}{c}\text { RF } \\
\text { power } \\
\text { (W) }\end{array}$ & $\begin{array}{c}\text { Working } \\
\text { distance } \\
(\mathrm{cm})\end{array}$ & $\begin{array}{c}\text { Sputtering } \\
\text { pressure } \\
\text { (mTorr) }\end{array}$ & $\begin{array}{c}\text { Deposition } \\
\text { time } \\
(\mathrm{h})\end{array}$ \\
\hline 1 & 150 & 8 & 1 & 0.5 \\
2 & 150 & 9 & 3 & 1 \\
3 & 150 & 10 & 5 & 2 \\
4 & 175 & 8 & 3 & 2 \\
5 & 175 & 9 & 5 & 0.5 \\
6 & 175 & 10 & 1 & 1 \\
7 & 200 & 8 & 5 & 1 \\
8 & 200 & 9 & 1 & 2 \\
9 & 200 & 10 & 3 & 0.5 \\
\hline
\end{tabular}

using a UV/Vis spectrometer (Mission peaks optics, MP100$\mathrm{M})$ equipped with an optical microscope. The instrument with multiple gratings measures to achieve the interference between incident and reflected light with a wide spectrum ranging from UV to visible range $(380-950 \mathrm{~nm})$ [28].

\section{Results and Discussion}

3.1. XPS and Microstructure Analysis of DLC Films. Figure 1 shows the response graph of the four factors versus $\mathrm{sp}^{3}$ content. The ranking of the order of the magnitude of the $\mathrm{sp}^{3}$ content ranges for various levels. The leading factor affecting process parameters is deposition time, followed successively by RF power, sputtering pressure, and working distance. XPS is employed to obtain the quantitative results of film composition $\left(\mathrm{sp}^{2}: \mathrm{sp}^{3}\right)$, which are chemically specific, as each element has its own core level. The deconvolution of the Cls peak of DLC film is obtained by an XPS curve fitted by using the three-curve methods. The $\mathrm{sp}^{3}$ fraction of DLC films was derived from XPS fitting for the Cls core peak, with peaks formed by diamond $(285.1 \mathrm{eV})$, graphite $(284.6 \mathrm{eV})$, and carbon-oxygen $(286.5 \mathrm{eV})$ bonds. The area of each peak depends on the corresponding phase. The $\mathrm{sp}^{3}$ content was estimated by taking the ratio of the diamond peak over the sum of the diamond, graphite, and carbon-oxygen bonds peak areas. In this study, each component was obtained by using a convolution of Gaussian (80\%) and Lorentzian (20\%) methods, and background subtraction was approximated by the Shirley method. The Gaussian widths of the spectra for DLC films are $1.35 \mathrm{eV}$, and the component depends on the

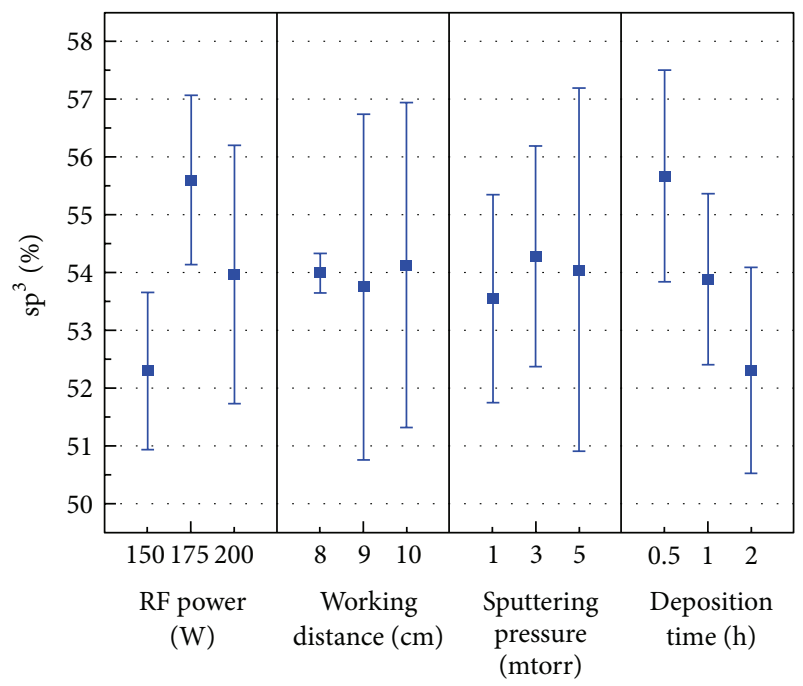

FIGURE 1: Response graph of the four factors versus $\mathrm{sp}^{3}$ content. The ranking order of the magnitude of $\mathrm{sp}^{3}$ content at various levels indicates that the effects of various factors on the $\mathrm{sp}^{3}$ content are ranked in the following order: deposition time, RF power, sputtering pressure, and working distance.

$\mathrm{sp}^{2}$ and $\mathrm{sp}^{3}$ hybridization results in each specimen shifted by $0.5 \mathrm{eV}$, as shown in Figure 2 [23-25]. According to the XPS results, the probable $\mathrm{sp}^{3}$ content of the specimens was reduced from $56.17 \%$ to $50.92 \%$ in correspondence with increased deposition time. The findings demonstrate that the content of the $\mathrm{sp}^{3}$ bonded carbon becomes lower in reference to the effect of the substrate temperature. The implantation of carbon ion during deposition generates heat and warms up the substrate rapidly. The deposition time increases from $0.5 \mathrm{~h}$ to $2 \mathrm{~h}$ when significantly increasing the temperature on the substrate. The high temperature of the substrate can partially release the compressive stress induced by carbon ion implantation and obstruct the formation of $\mathrm{sp}^{3}$ bonds. The results can affect transform of the $\mathrm{sp}^{3}$ bond into an $\mathrm{sp}^{2}$ bond [29]. On the other hand, this study assumes that the $\mathrm{sp}^{3}$ content varies with RF power. For an RF power of $150 \mathrm{~W}$, the low proportion of $\mathrm{sp}^{3}$ bond in the thin film was formed from the diamond target via the sputtering process owing to the low bombardment energy. The bombardment energy is enhanced on the Ar plasma at the RF power of $175 \mathrm{~W}$, indicating that the bonds of diamond can be broken by powerful bombarding atoms [10].

Figure 3 shows the typical plan view surface of SEM images, and the insets display the cross view. The results showed that as-deposited DLC films are considerable smooth morphology; the shrink and warped deformations were not observed from the surface of thin films. Figure 3(d) shows cross view of DLC film (specimen GD 3), indicating that the thickness is $30 \mathrm{~nm}$. Through SEM analysis results, it clearly indicated never the existence of highly internal stress in such a thick DLC films leading to films peeling off from the D263T glass substrate. Figure 4 indicates the hardness of the DLC films analyzed by the nanoindentation test with a 


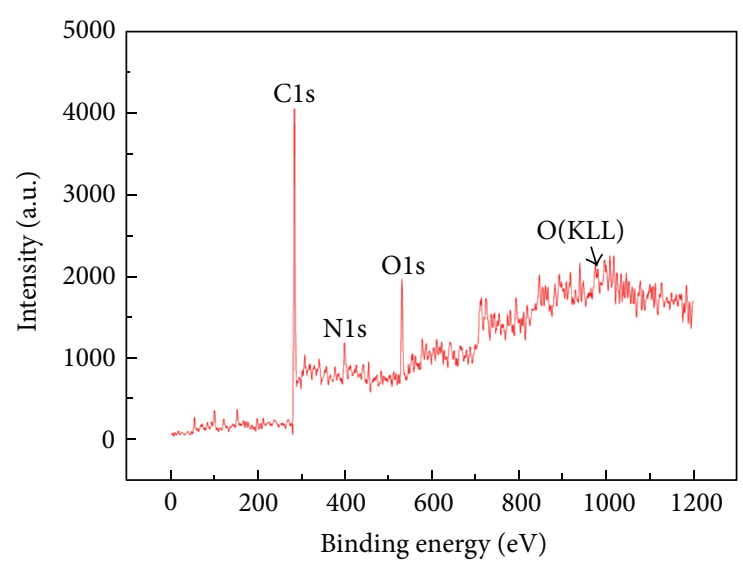

(a)

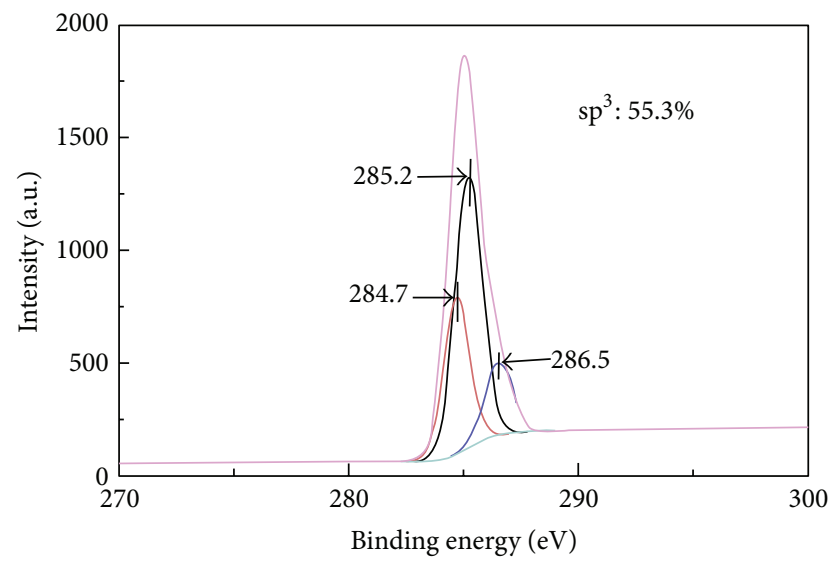

(c)

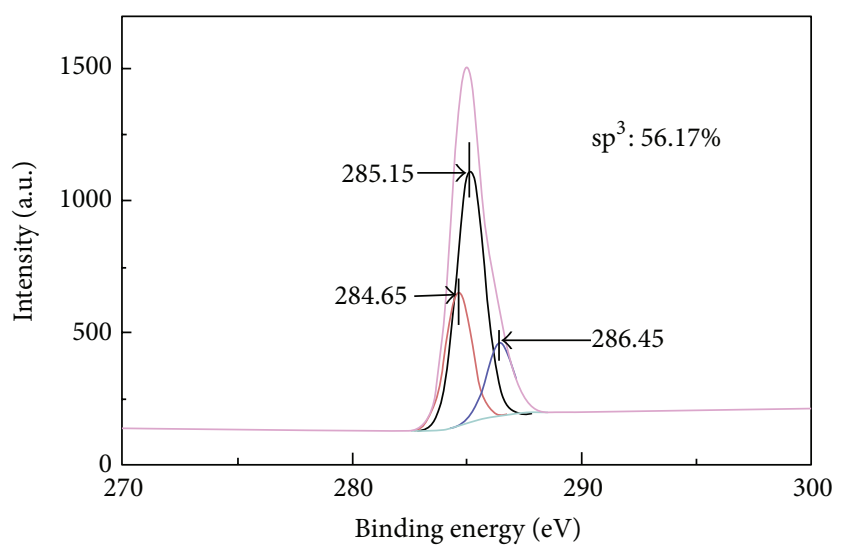

(b)

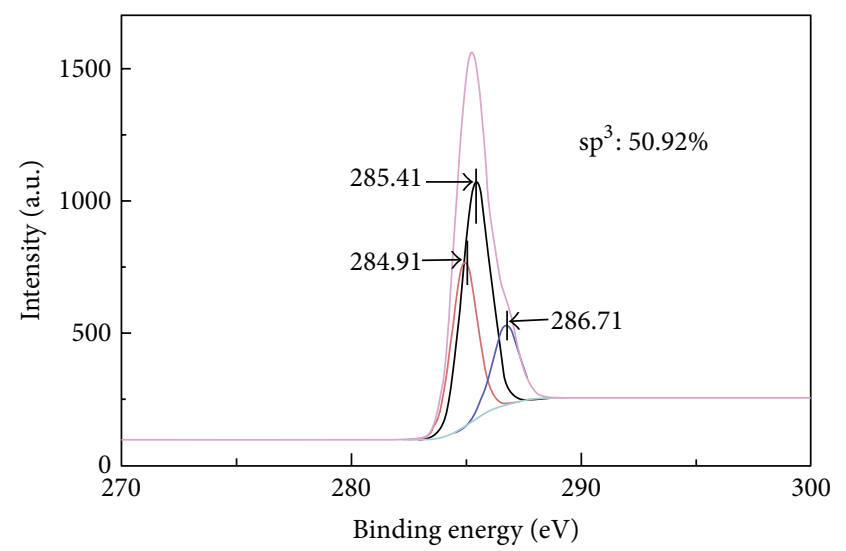

(d)

FIGURE 2: XPS survey spectrum (a) and the deconvolution of the Cls binding energy peak of the XPS spectrum of the DLC films; (b) DLC film (specimen GD 9) deposited under a sputtering power of $200 \mathrm{~W}$, work distance of $10 \mathrm{~cm}$, working pressure of 3 mTorr, and deposition time of 0.5 h. (c) DLC film (specimen GD 6) deposited under the sputtering power of $175 \mathrm{~W}$, work distance of $10 \mathrm{~cm}$, working pressure of $1 \mathrm{mTorr}$, and deposition time of $1 \mathrm{~h}$. (d) DLC film (specimen GD 3) deposited under the sputtering power of $150 \mathrm{~W}$, work distance of $10 \mathrm{~cm}$, working pressure of $5 \mathrm{mTorr}$, and deposition time of $2 \mathrm{~h}$.

large loading of $500 \mu \mathrm{N}$. A scanning probe microscopy (SPM) apparatus was used to conduct nanofriction, nanowear, and fractal investigations to determine the nanotribological characteristics of the deposited DLC films. Fractal analysis is applied to quantitatively characterize the surface roughness of films measured by AFM. The aforementioned NIP test results showed that the hardness behaviors of all as-deposited DLC films improved significantly with the increase of the $\mathrm{sp}^{3}$ content, and the hardness of the as-deposited films was greater than 13.2 GPa.

3.2. RMS Surface Roughness Analysis of DLC Films. Figure 5 shows the response graph of the four factors versus RMS surface roughness. The ranking of the order of the magnitude of the RMS surface roughness differs at various levels, indicating that the effects of various factors on the RMS surface roughness increase in accordance with sputtering pressure, deposition time, working distance, and RF power. The surface roughness values of DLC films have been obtained by AFM analysis. AFM measurements presented here were obtained in the tapping mode, using a Digital Instruments Nanoscope machine. Typical scan areas were over $30 \times 30 \mu \mathrm{m}^{2}$, and the scan rate was approximately $1 \mathrm{~Hz}$. Surface RMS roughness was obtained from a complete scan, using the software supplied with the AFM system. From this measurement it is clear that all as-deposited DLC films were lower than $1.9 \mathrm{~nm}$ with a scanning area of $30 \times 30 \mu \mathrm{m}^{2}$, and the RMS surface roughness in the DLC films was improved significantly with the decrease of the sputtering pressure. In this study, the formation of nanoparticles during vapor deposition strongly depends on the sputter pressure. At higher plasma pressure, there is an increase in the number of inelastic collisions which leads to a decrease in the diffusivity of carbon in the D263T glass substrate owing to the significantly reduced energies. Thus, the films deposited at higher plasma pressure demonstrate an increased RMS surface roughness. At low pressures, it is evident that smooth DLC films are formed. This result is consistent with previous results, and this can be understood on the basis of the large differences between the atomic masses of carbon and argon which causes carbon 


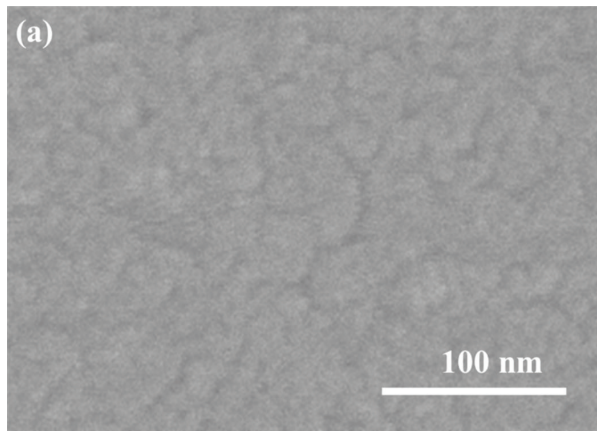

(a)

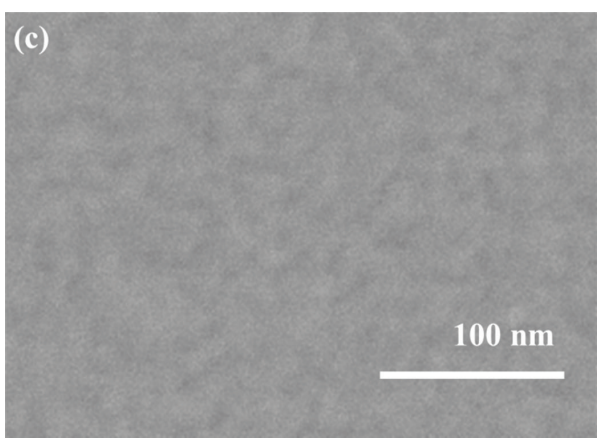

(c)

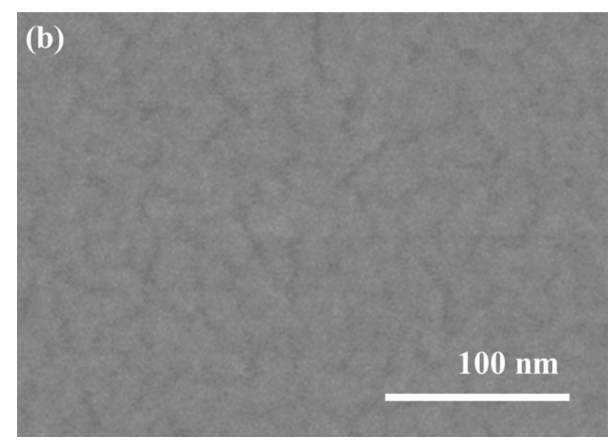

(b)

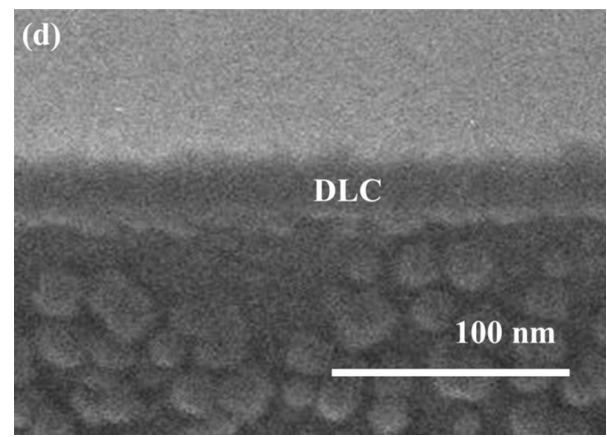

(d)

FIGURE 3: SEM images of DLC film are deposited on D263T glass substrate at room temperature by using RF magnetron sputtering technique. (a) SEM images of DLC film deposited referred to the specimen GD 9. (b) SEM images of DLC film deposited referred to the specimen GD 6. (c) SEM images of DLC film deposited referred to the specimen GD 3, and (d) the cross-section view shows the corresponding for image (c), which is $30 \mathrm{~nm}$ thick DLC film.

atoms to lose most of their kinetic energies before reaching the substrate at higher plasma pressures. This is expected to lead to the formation of thin film with high surface roughness [30].

3.3. Hydrophobicity Analysis of DLC Films. Figure 6 shows a response graph of four factors versus contact angle. The ranking order of the magnitude of contact angle at various levels indicates that the effects of various factors on the contact angle are ranked in the following order: RF power, deposition time, working distance, and sputtering pressure. A number of researchers have reported that the contact angle depends on the $\mathrm{sp}^{3}$ content of the film. It may be that hydrophobicity significantly decreases with the increase of $\mathrm{sp}^{2}$ bonded carbon in the films. The findings of this study may demonstrate that the surface energy varies at different carbon hybridized states, which modify the surface properties and associated hydrophobic/hydrophilic behavior. The surface energy of the $\mathrm{sp}^{3}$ terminated surface is very high because of its strong covalent character compared with that of the $\mathrm{sp}^{2}$ terminated surface as $\mathrm{sp}^{2}$ bonded graphite exhibits weak polarity due to its dangling bonds [31-33]. In this study, the DLC films under the RF power of $175 \mathrm{~W}$ show higher hydrophobicity than those under the RF power of $150 \mathrm{~W}$ and $200 \mathrm{~W}$. It is clear that those films have high $\mathrm{sp}^{3}$ carbon content. Thus, the wetting contact angle of DLC films can be modified and controlled by the variation of $\mathrm{sp}^{3}$ content to obtain a hydrophobic or hydrophilic surface property.

3.4. Optical Properties Analysis of DLC Films. Figure 7 illustrates the response graph of four factors versus transmittance. The ranking order of the magnitude of transmittance at various levels indicates that the effects of various factors on the transmittance are ranked in the following order: RF power, deposition time, working distance, and sputtering pressure. The UV/Vis spectrophotometer shows that the optical properties of the films deposited with a single DLC layer are obtained from the five-point position of the films onto D263T glass. Figure 8 shows the refraction spectra for the D263T glass substrates coated with and without DLC films prepared under the sputtering process parameters, and the thickness of the as-deposited amorphous DLC films ranges from 17 to $66 \mathrm{~nm}$. From the previous results, the values of the RMS roughness surface of the thin films are lower than $1.9 \mathrm{~nm}$. It can be concluded that the effect of light scattering from the thin films was negligible. Thus, the reflectance of the thin films was decreased significantly with increasing transmittance. The reflectance in the visible wavelengths (at $\lambda=400-700 \mathrm{~nm}$ ) significantly increases with increasing RF power. This is associated with the larger thickness. The total reflection changes with the refraction indices of the films and substrate, $n$ and $n s$, respectively. As the refraction index of the substrate, $n s$, is larger than that of thin films, $n$, the resultant 


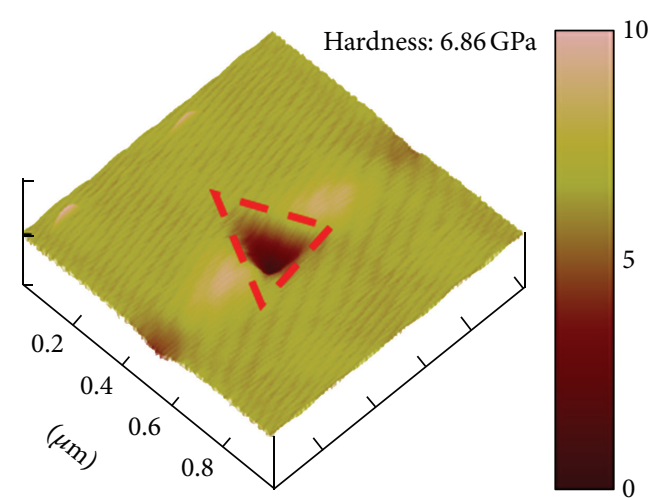

(a)

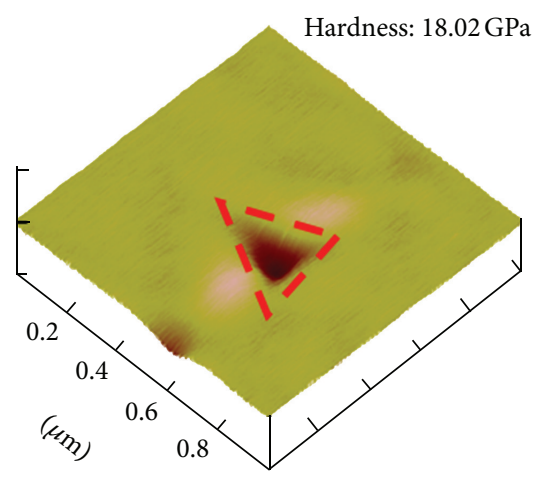

(c)

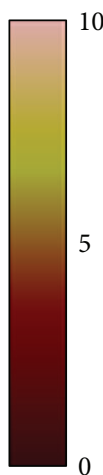

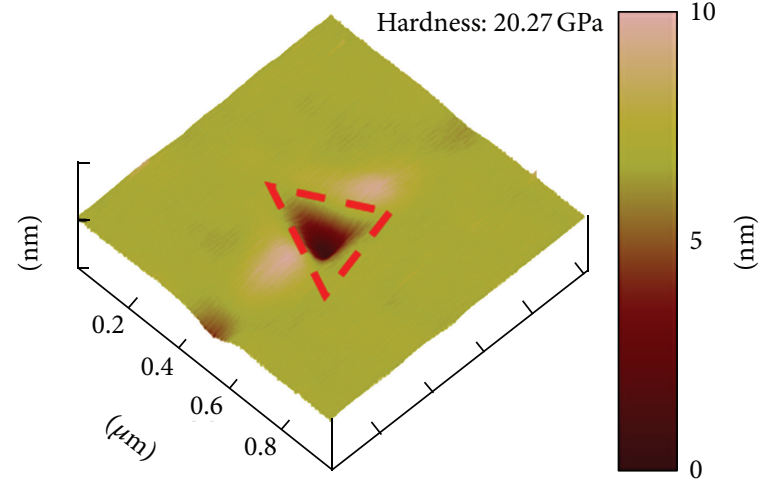

(b)

ఏ્తి

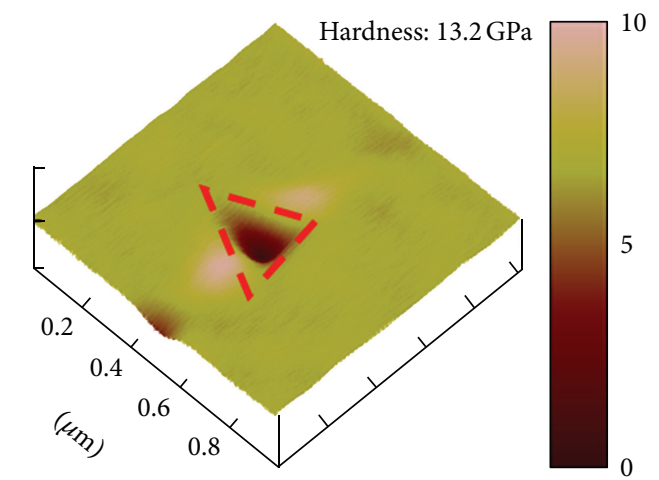

(d)

FIGURE 4: AFM topography after the nanoindentation test for the D263T glass substrates coated with and without DLC films prepared under a large load of $500 \mu \mathrm{N}$ : (a) D263T glass substrates, (b) specimen GD 9, (c) specimen GD 6, and (d) specimen GD 3.

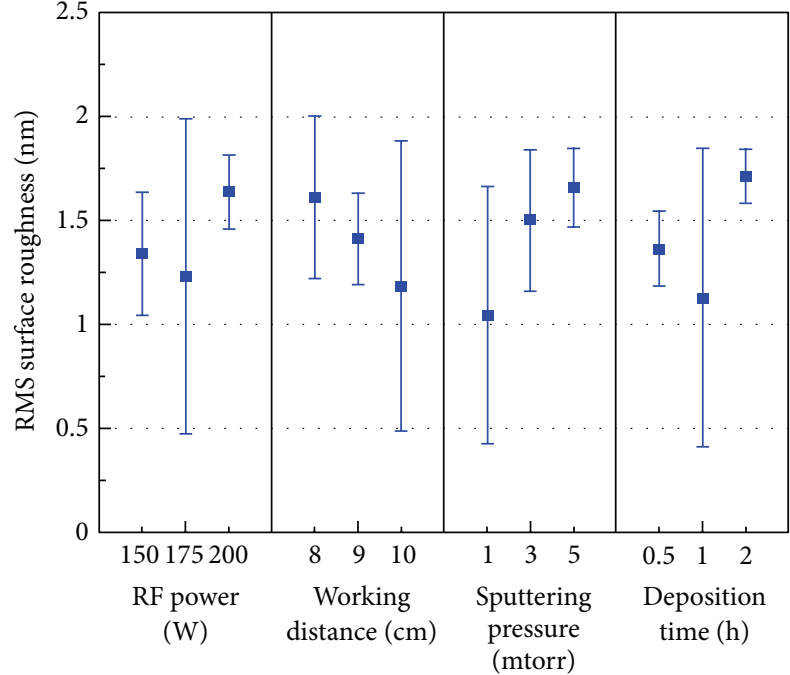

FIGURE 5: Response graph of four factors versus RMS surface roughness. The ranking order of the magnitude of RMS surface roughness at various levels indicates that the effects of various factors on the RMS surface roughness are ranked in the following order: sputtering pressure, deposition time, working distance, and RF power.

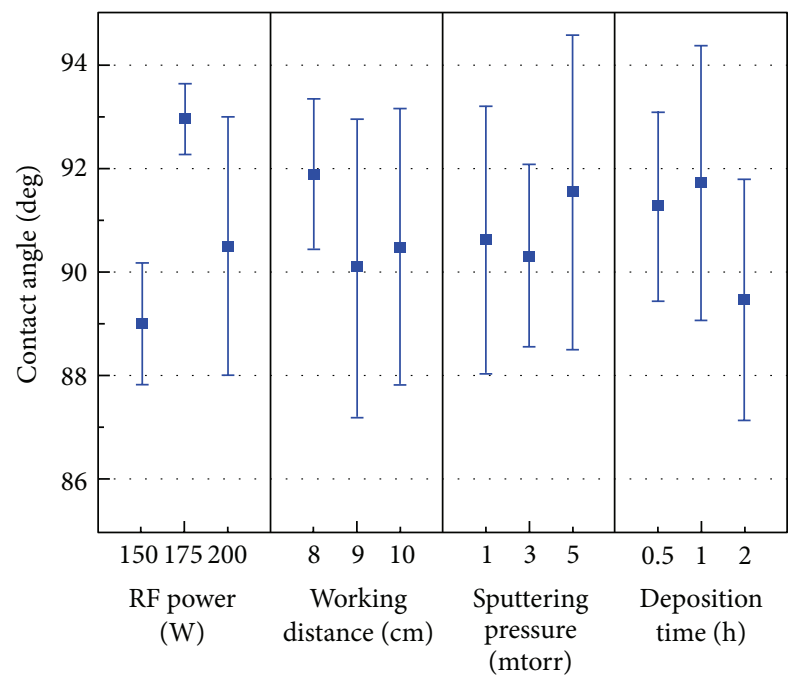

FIGURE 6: Response graph of four factors versus contact angle. The ranking of the order of the magnitude of the contact angle differs at various levels, indicating that the effects of various factors on the contact angle increasing in accordance with RF power, deposition time, working distance, and sputtering pressure. 


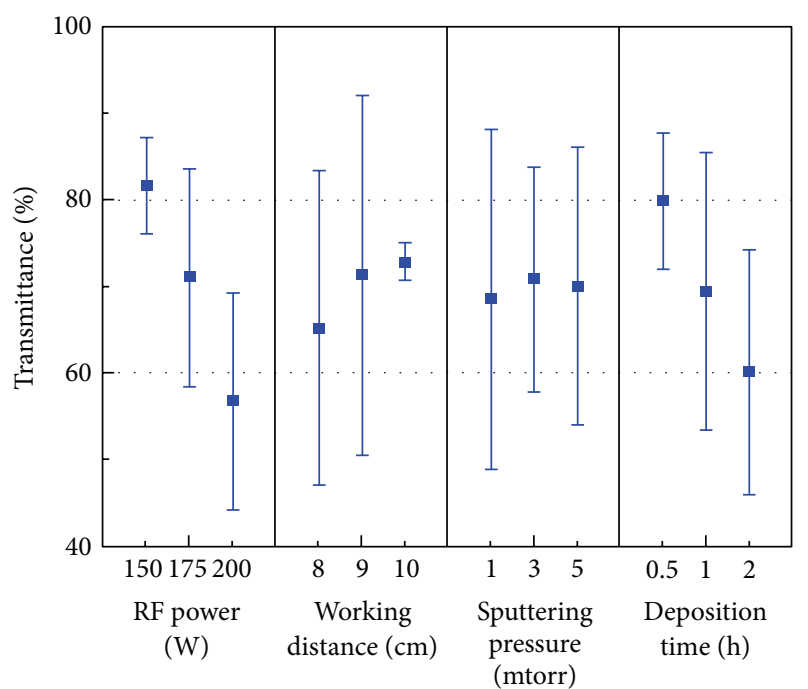

FIGURE 7: Response graph of the four factors versus transmittance. The ranking of the order of magnitude of transmittance for various levels indicates that the effects of various factors on the transmittance are ranked in the following order: RF power, deposition time, working distance, and sputtering pressure.

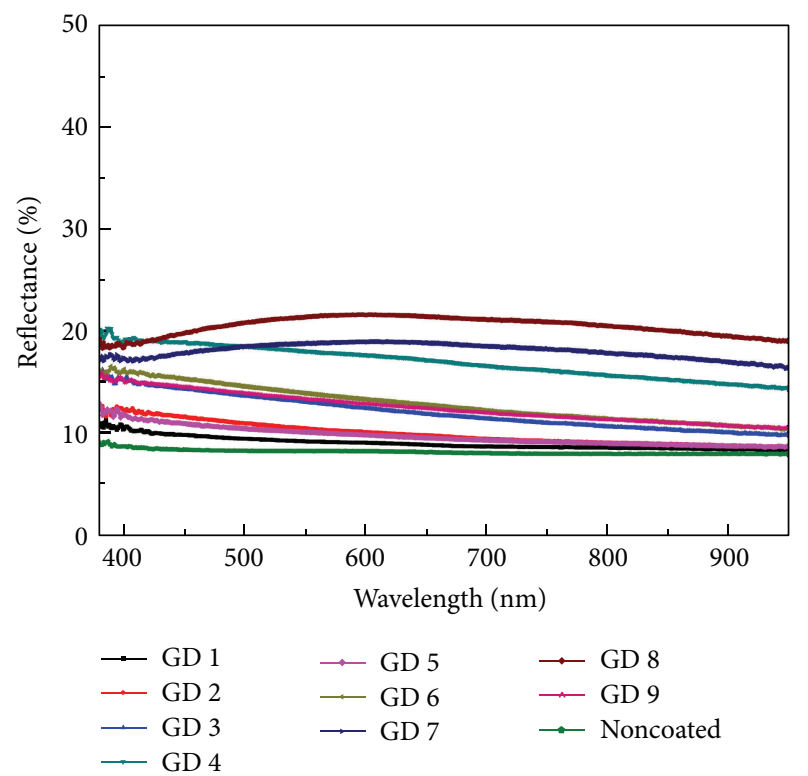

FIGURE 8: The various average reflectance of DLC films deposited by RF magnetron sputtering onto D263T glass.

reflection will be reduced. This is referred to as constructive interference or broken interference [10]. In this study, the reflectance of the as-deposited DLC films is higher than that of the noncoated one. This indicates that the refraction index of thin films is larger than that of the substrate one. The refraction index $(n)$ of D263T glass substrate is 1.52 . The UV/Vis spectrophotometer measurements show that the refraction index $(n)$ of all as-deposited DLC films ranges from 1.95 to 2.1 at $\lambda=600 \mathrm{~nm}$. These results demonstrate that the thickness was increased correspondingly with the increasing reflectance. On the other hand, under an RF power of $150 \mathrm{~W}$ and a deposition time of $0.5 \mathrm{~h}$, the specimen GD 1 had high transmissive ability $(>81 \%)$ and low average reflectance ability $(<9.5 \%)$ in the visible wavelengths (at $\lambda=400-700 \mathrm{~nm}$ ). This result could make an antireflection coating for solar cell devices available, which would improve efficiency [9].

\section{Conclusions}

The present work shows that DLC films have been successfully deposited onto D263T glass substrate at room temperature via a diamond powder target using the radio frequency (RF) magnetron sputtering technique and Taguchi method. Experimental results show that the content of $\mathrm{sp}^{3}$ bonded carbon decreases due to the effect of substrate temperature. The NIP test results showed that the hardness of the prepared DLC films ranges from 13.2 to $22.5 \mathrm{GPa}$. Moreover, the water repellence of the deposited DLC films improved significantly with increasing $\mathrm{sp}^{3}$ content, and its contact angle is larger than that of the noncoated one by 1.45 times. The reflectance in the visible wavelengths (at $\lambda=400-700 \mathrm{~nm}$ ) significantly increases with increasing RF power, which is considered to be associated with the larger thickness. In addition, the refraction index $(n)$ of all as-deposited DLC films ranges from 1.95 to 2.1 at $\lambda=600 \mathrm{~nm}$. Furthermore, when the RF power was set to $150 \mathrm{~W}$ with the deposition time of $0.5 \mathrm{~h}$, the prepared DLC films possessed high transmissive ability $(>81 \%)$ and low average reflectance ability $(<9.5 \%)$ in the visible wavelengths (at $\lambda=400-700 \mathrm{~nm}$ ).

\section{Acknowledgment}

This work was financially supported by the main research projects of the National Science Council of the China under Grant nos. NSC 101-2221-E-027-009.

\section{References}

[1] R.-H. Horng, W.-C. Kao, S.-L. Ou, and D.-S. Wuu, "Effect of diamond like carbon layer on heat dissipation and optoelectronic performance of vertical-type InGaN light emitting diodes," Applied Physics Letters, vol. 101, no. 17, Article ID 171102, 2012.

[2] J. Wang, F. Liu, H. Chen, and D. Chen, "Superhydrophobic behavior achieved from hydrophilic surfaces," Applied Physics Letters, vol. 95, no. 8, Article ID 084104, 2009.

[3] C. R. Lin, C. H. Su, P. S. Fan, and K. L. Wang, "Application of nitrified steel deposit diamond-like carbon film in explosive environment," Japanese Journal of Applied Physics, vol. 47, no. 4, pp. 2221-2224, 2008.

[4] J. A. Johnson, J. B. Woodford, D. Rajput et al., "Carbonhydrogen bonding in near-frictionless carbon," Applied Physics Letters, vol. 93, no. 13, Article ID 131911, 2008.

[5] T. Patrusheva, V. Letunovsky, L. Gorjacheva, A. Gorschkov, V. Sergienko, and E. Jakovleva, "Protective coatings from ultra fine diamond," Carbon, vol. 40, no. 1, pp. 125-129, 2002.

[6] C. R. Lin, D. H. Wei, C. K. Chang, W. H. Liao, and K. Ran Peng, "Diamond-like carbon films deposited at room temperature on 
flexible plastics substrates for antireflection coating," Japanese Journal of Applied Physics, vol. 50, no. 3, Article ID 035802, 2011.

[7] S. Sahoo, S. S. Pradhan, V. Bhavanasi, and S. K. Pradhan, "Structural and mechanical characterization of diamond like carbon films grown by microwave plasma CVD," Surface and Coatings Technology, vol. 204, no. 16-17, pp. 2817-2821, 2010.

[8] S. B. Singh, M. Pandey, N. Chand et al., "Optical and mechanical properties of diamond like carbon films deposited by microwave ECR plasma CVD," Bulletin of Materials Science, vol. 31, no. 5, pp. 813-818, 2008.

[9] W. S. Choi, K. Kim, J. Yi, and B. Hong, "Diamond-like carbon protective anti-reflection coating for Si solar cell," Materials Letters, vol. 62, no. 4-5, pp. 577-580, 2008.

[10] C. H. Su, C. R. Lin, C. Y. Chang, H. C. Hung, and T. Y. Lin, "Mechanical and optical properties of diamond-like carbon thin films deposited by low temperature process," Thin Solid Films, vol. 498, no. 1-2, pp. 220-223, 2006.

[11] J. Robertson, "Properties of diamond-like carbon," Surface and Coatings Technology, vol. 50, no. 3, pp. 185-203, 1992.

[12] V. M. Aroutiounian, K. Martirosyan, and P. Soukiassian, "Low reflectance of diamond-like carbon/porous silicon double layer antireflection coating for silicon solar cells," Journal of Physics D, vol. 37, no. 19, pp. L25-L28, 2004.

[13] Y. Hayashi, S. Ishikawa, T. Soga, M. Umeno, and T. Jimbo, "Photovoltaic characteristics of boron-doped hydrogenated amorphous carbon on $\mathrm{n}$-Si substrate prepared by r.f. plasmaenhanced CVD using trimethylboron," Diamond and Related Materials, vol. 12, no. 3-7, pp. 687-690, 2003.

[14] W.-H. Liao, C. -R. Lin, D.-H. Wei et al., "Concurrent improvement in biocompatibility and bioinertness of diamond-like carbon films with nitrogen doping," Journal of Biomedical Materials Research Part A, vol. 100, no. 11, pp. 3151-3156, 2012.

[15] Y. Lifshitz, G. D. Lempert, E. Grossman et al., "Optical and photoemission studies of DLC films prepared with a systematic variation of the sp3:sp2 composition," Diamond and Related Materials, vol. 6, no. 5-7, pp. 687-693, 1997.

[16] M. Smietana, W. J. Bock, J. Szmidt, and J. Grabarczyk, "Substrate effect on the optical properties and thickness of diamond-like carbon films deposited by the RF PACVD method," Diamond and Related Materials, vol. 19, no. 12, pp. 1461-1465, 2010.

[17] M. H. Oliveira, D. S. Silva, A. D. S. Côrtes, M. A. B. Namani, and F. C. Marques, "Diamond like carbon used as antireflective coating on crystalline silicon solar cells," Diamond and Related Materials, vol. 18, no. 5-8, pp. 1028-1030, 2009.

[18] Y.-S. Yang and W. Huang, "A grey-fuzzy Taguchi approach for optimizing multi-objective properties of zirconium-containing diamond-like carbon coatings," Expert Systems with Applications, vol. 39, no. 1, pp. 743-750, 2012.

[19] M. Hamidi, A. Azadi, H. Ashrafi, P. Rafiei, and S. MohamadiSamani, "Taguchi orthogonal array design for the optimization of hydrogel nanoparticles for the intravenous delivery of smallmolecule drugs," Journal of Applied Polymer Science, vol. 126, no. 5, pp. 1714-1724, 2012.

[20] A. Czyzniewski, "Optimising deposition parameters of W-DLC coatings for tool materials of high speed steel and cemented carbide," Vacuum, vol. 86, no. 12, pp. 2140-2147, 2012.

[21] A. H. Tan and Y. C. Cheng, "Optimization of wear-corrosion properties of a-C:N films using filtered cathodic arc deposition," Diamond and Related Materials, vol. 17, no. 1, pp. 36-42, 2008.

[22] N. Ali, V. F. Neto, S. Mei et al., "Optimisation of the new timemodulated CVD process using the Taguchi method," Thin Solid Films, vol. 469-470, pp. 154-160, 2004.
[23] T. Y. Leung, W. F. Man, P. K. Lim, W. C. Chan, F. Gaspari, and S. Zukotynski, "Determination of the sp3/sp2 ratio of a-C:H by XPS and XAES," Journal of Non-Crystalline Solids, vol. 254, no. 1-3, pp. 156-160, 1999.

[24] J. Filik, P. W. May, S. R. J. Pearce, R. K. Wild, and K. R. Hallam, "XPS and laser Raman analysis of hydrogenated amorphous carbon films," Diamond and Related Materials, vol. 12, no. 3-7, pp. 974-978, 2003.

[25] Z. G. Lu and C. Y. Chung, "Electrochemical characterization of diamond like carbon thin films," Diamond and Related Materials, vol. 17, no. 11, pp. 1871-1876, 2008.

[26] J. B. Wu, J. J. Chang, M. Y. Li, M. S. Leu, and A. K. Li, "Characterization of diamond-like carbon coatings prepared by pulsed bias cathodic vacuum arc deposition," Thin Solid Films, vol. 516, no. 2-4, pp. 243-247, 2007.

[27] K. Bewilogua, C. V. Cooper, C. Specht, J. Schröder, R. Wittorf, and M. Grischke, "Effect of target material on deposition and properties of metal-containing DLC (Me-DLC) coatings," Surface and Coatings Technology, vol. 127, no. 2-3, pp. 224-232, 2000.

[28] C. M. Chuang, M. C. Wu, W. F. Su, K. C. Cheng, and Y. F. Chen, "High intensity fluorescence of photoactivated silver oxide from composite thin film with periodic array structure," Applied Physics Letters, vol. 89, no. 6, Article ID 061912, 2006.

[29] X. Z. Che, L. H. Chen, H. T. Ma, and H. X. Fang, "Effect of thickness on structures of ultrathin diamond-like carbon films," Chinese Science Bulletin, vol. 55, no. 18, pp. 1949-1951, 2010.

[30] R. Maheswaran, R. Sivaraman, O. Mahapatra, P. C. Rao, C. Gopalakrishnan, and D. J. Thiruvadigal, "Surface studies of diamond-like carbon films grown by plasma-enhanced chemical vapor deposition," Surface and Interface Analysis, vol. 42, no. 12-13, pp. 1702-1705, 2010.

[31] J. Robertson, “Diamond-like amorphous carbon," Materials Science and Engineering R, vol. 37, pp. 129-281, 2002.

[32] Y. Zhou, B. Wang, X. Song et al., "Control over the wettability of amorphous carbon films in a large range from hydrophilicity to super-hydrophobicity," Applied Surface Science, vol. 253, no. 5, pp. 2690-2694, 2006.

[33] R. Paul, S. N. Das, S. Dalui et al., "Synthesis of DLC films with different sp2/sp3 ratios and their hydrophobic behaviour," Journal of Physics D, vol. 41, no. 5, Article ID 055309, 2008. 

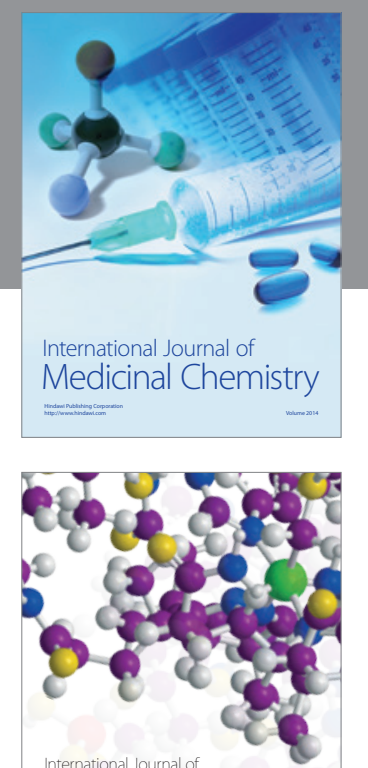

\section{Carbohydrate} Chemistry

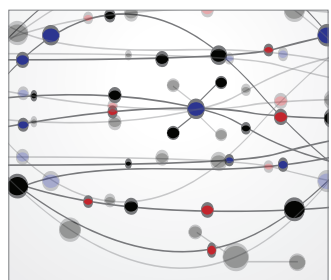

The Scientific World Journal
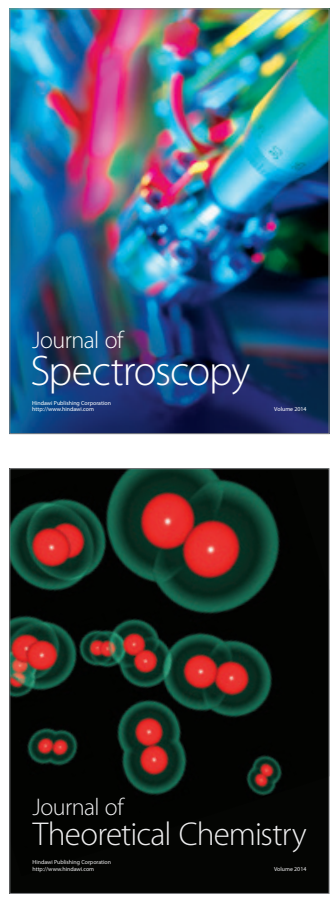
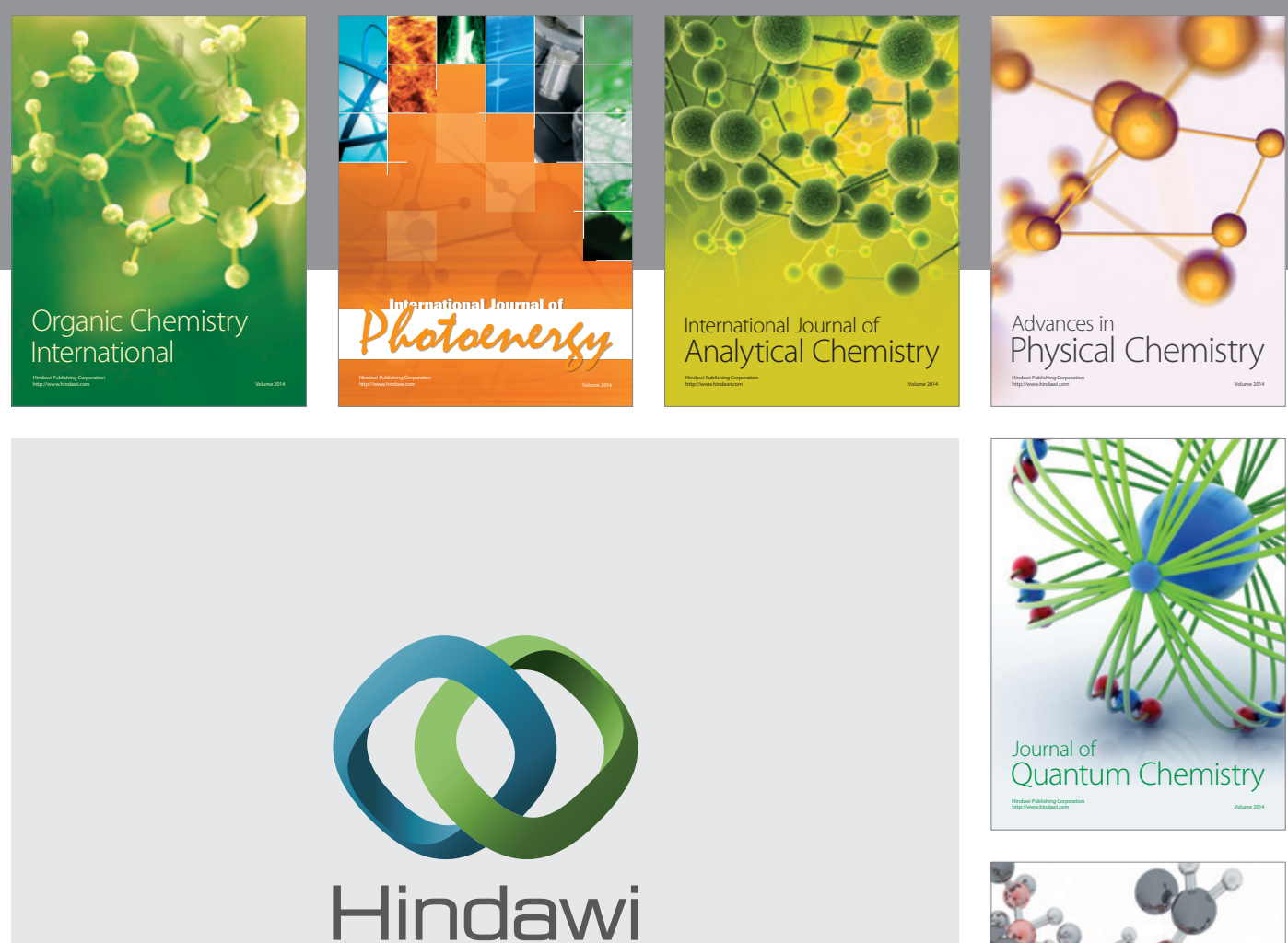

Submit your manuscripts at

http://www.hindawi.com

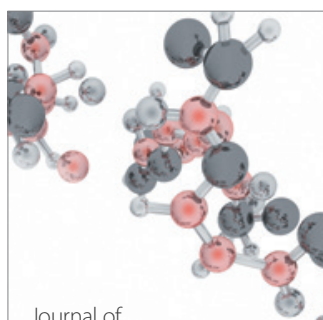

Analytical Methods

in Chemistry

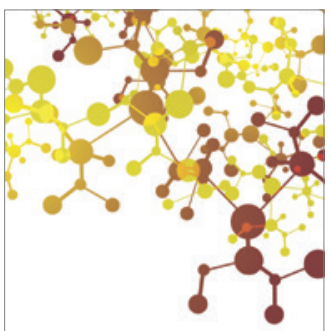

Journal of

Applied Chemistry

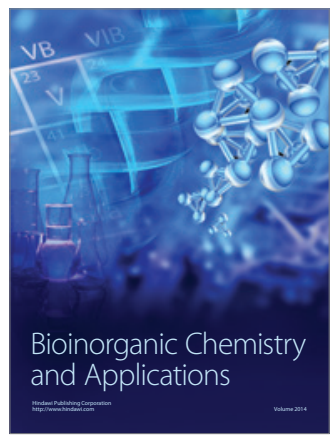

Inorganic Chemistry
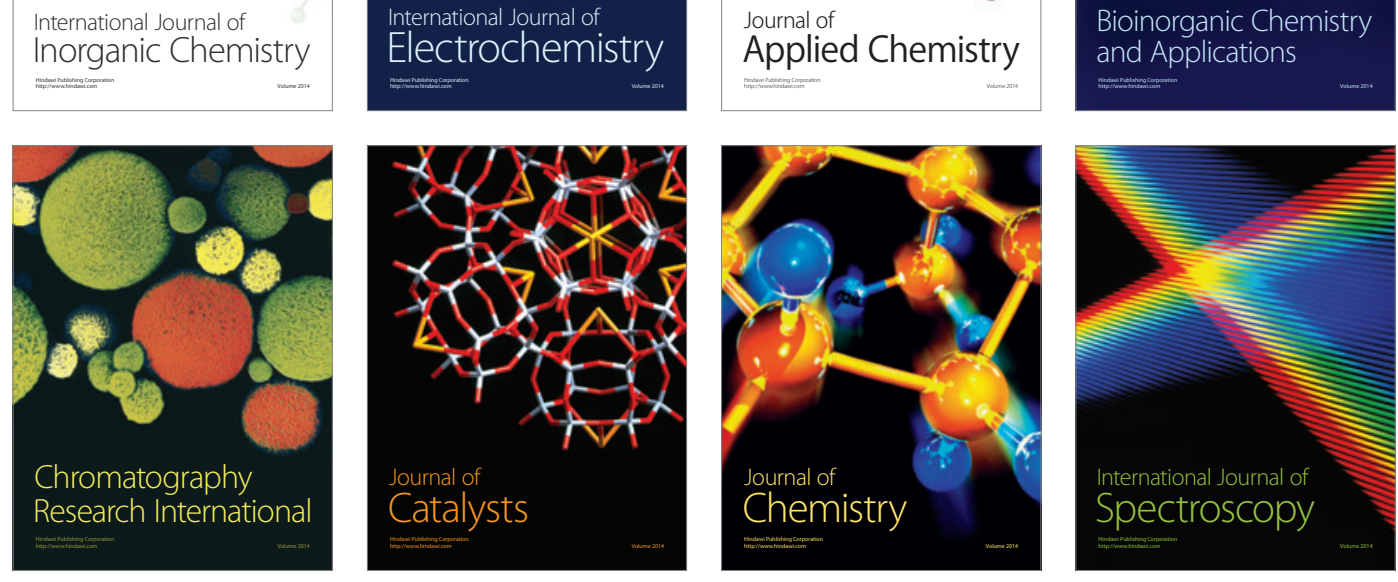